\title{
Impétigo herpetiforme recurrente: manejo exitoso con ciclosporina
}

\author{
Enrique Valdés R, Tatiana N úñez U ${ }^{1}$, Daniel Pedraza S, \\ Hernán Muñoz S.
}

Recurrent impetigo herpetiformis: Successfully managed with ciclosporine. Report of one case

Impetigo Herpetiformis is a high-risk gestational skin disease that represents a risk for both the mother and offspring. Its management is based on multisystemic support and maternal steroid therapy. When these measures are insufficient to control the disease, the association of ciclosporine to the treatment has been proposed. We report a 24 yearold woman with a 16 weeks pregnancy, that presented with Impetigo Herpetiformis. The disease was refractory to the use of steroids, the patient had a metabolic decompensation and a dehydration with electrolyte imbalance. Therefore, treatment with ciclosporine was initiated and a rapid regression of the lesions was observed. Gestation was maintained, with a good perinatal outcome (Rev Méd Chile 2005; 133: 1071-74).

(Key Words: Adrenal cortex hormones; Cyclosporine; Impetigo)

Recibido el 15 de marzo, 2005. Aceptado el 24 de mayo, 2005.

Unidad de Medicina Fetal y Perinatal, Departamento de Obstetricia y Ginecología, Hospital Clínico Universidad de Chile.

${ }^{1}$ Becaria de Obstetricia y Ginecología, Hospital Clínico Universidad de Chile.

$\mathrm{D}$ esde que Hebra, en 1872, describió por primera vez esta enfermedad de rara ocurrencia ${ }^{1}$, el pronóstico feto-materno del impétigo herpetiforme (IH) ha presentado una gran mejoría, secundaria esencialmente al apoyo clínico multidisciplinario al binomio madre-hijo y a la corticoterapia. Cuando estas medidas son insuficientes para el control de la enfermedad se ha

Correspondencia a: Dr. Enrique Valdés R. Santos Dumont 999, Independencia. Santiago, Chile. Teléfonos: (56-2) 6788101-09-5345963. Fax: 3344407. E mail: evaldes@ns.hospital.uchile.cl o kivalru@terra.cl planteado la asociación terapéutica con ciclosporina.

Se presenta un caso clínico de impétigo herpetiforme recidivado en un segundo embarazo y refractario al tratamiento de apoyo multisistémico y corticoidal, por lo que se decidió asociar terapia con ciclosporina, obteniéndose una buena respuesta clínica materna y un buen resultado perinatal.

\section{CASO CLÍNICO}

Paciente de 24 años, con antecedentes de psoriasis en control desde los 12 años; fórmula obstétri- 
ca G2P1A0. Durante su primer embarazo se diagnosticó IH, éste finalizó a las 32 semanas por muerte fetal intrauterina, al parecer debida a descompensación metabólica por cuadro base o a intolerancia a hidratos de carbono secundaria a corticoterapia en altas dosis. Durante el puerperio, el cuadro dermatológico regresó ad-integrum. La paciente desarrolló en el posparto trastorno de personalidad adaptativo reactivo (síndrome ansioso-depresivo).

La paciente cursaba su segundo embarazo, presentando desde la semana 16 de gestación cuadro clínico caracterizado por progresivo compromiso del estado general, fiebre, artralgias y placas dérmicas eritematosas, descamativas y lesiones pustulosas dolorosas de rápida evolución centrífuga afectando cara, tronco, genitales y extremidades, comprometiendo $60 \%$ de la superficie corporal (Figura 1).

Evaluada con dermatólogos, se concluyó que el cuadro clínico era compatible con $\mathrm{IH}$, lo que fue confirmado por biopsia de piel la que descri-

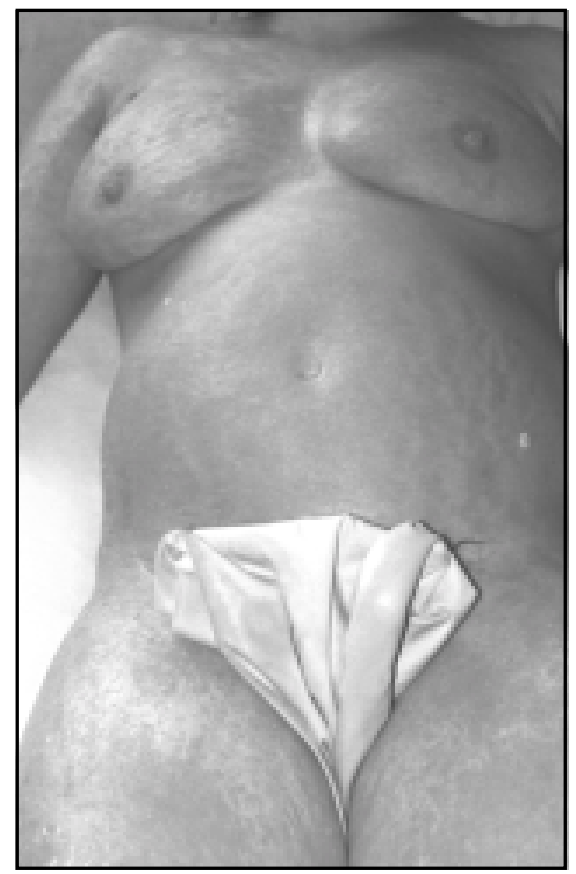

Figura 1. Paciente cursando embarazo de 16 semanas de gestación, nótese placas dérmicas eritematosas descamativas y lesiones pustulosas dolorosas de progresión centrífuga (cara, tronco y extremidades). bió una epidermis con evidencia de elongación regular de crestas interpapilares, papilomatosis, paraqueratosis y numerosos acúmulos de neutrófilos intraepidérmicos e intracórneos, sin colonización de colonias bacterianas ni de hifas con la tinción histoquímica de PAS. En dermis se observó vasodilatación y acúmulos locales de neutrófilos y linfocitos. Informe anatomopatológico concluyó dermatitis psoriasiforme compatible con IH (Figura 2).

La ultrasonográfica informó feto único con anatomía normal, creciendo en percentil 50 para su edad gestacional, oligohidroamnios y estudio doppler de territorio materno-fetal dentro de límites normales.

Se inició tratamiento con glucocorticoides sistémicos (prednisona $60 \mathrm{mg} /$ día), terapia tópica y medidas de sostén tendientes a corregir la deshidratación, el desbalance electrolítico y la hipoalbuminemia.

La paciente tuvo una regresión parcial de lesiones cutáneas y normalizó su volumen de líquido amniótico, presentando a la 27 semana de gestación eritrodermia con intensa exfoliación,

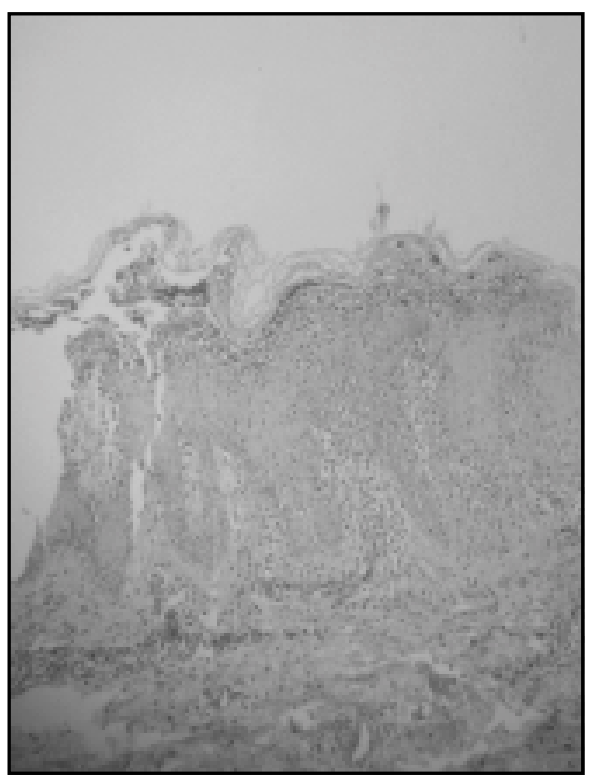

Figura 2. Biopsia de piel evidenciando elongación regular de crestas interpapilares, papilomatosis, paraqueratosis e infiltración de neutrófilos a nivel intraepidérmico e intracorneal (hematoxilina-eosina x10). 


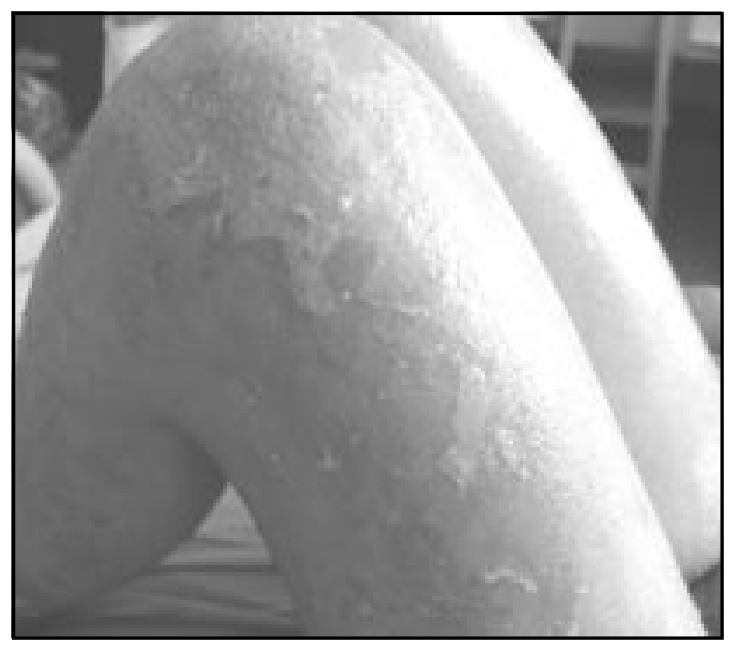

Figura 3. Paciente a las 27 semanas de gestación que a pesar de terapia corticoidal realiza una reagudización de su cuadro, nótese la eritrodermia con intensa exfoliación.

prurito y artralgias (Figura 3), asociado a descompensación del metabolismo de los hidratos de carbono secundario, al parecer, a terapia corticoidal (glicemia: $253 \mathrm{mgs} / \mathrm{dl}$ ), por lo que se decidió indicar insulinoterapia, se disminuyó paulatinamente las dosis de prednisona hasta llegar a una dosis de mantención de $20 \mathrm{mg} /$ día asociada a ciclosporina $(2,5 \mathrm{mg} / \mathrm{kg} /$ día, administrada en dos dosis, vía oral) con lo que se logró estabilización metabólica de la paciente y una rápida regresión de las lesiones cutáneas (Figura 4).

Debido al grave deterioro del cuadro psiquiátrico de base, se decidió la interrupción del embarazo a las 34 semanas, por vía alta, obteniéndose un recién nacido de sexo masculino, adecuado para la edad gestacional (2.680 grs) y con APGAR de 9 a los cinco minutos.

A los pocos días posparto, la paciente presentó regresión total de las lesiones cutáneas. Las dosis de ciclosporina y prednisona fueron reducidas gradualmente, retirándolas por completo a las seis semanas del parto.

\section{DisCUSIÓN}

El IH, una variante de la psoriasis pustulosa, es una patología gestacional de alto riesgo tanto para la

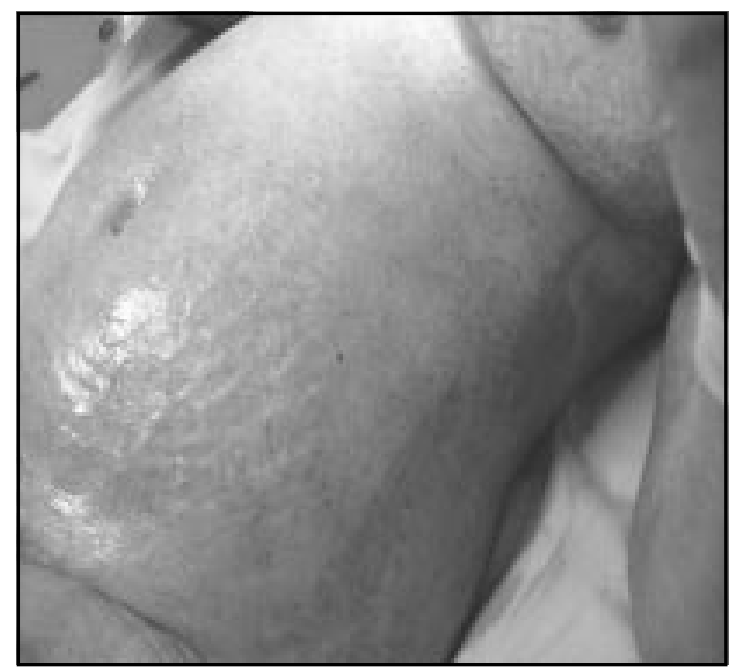

Figura 4. Paciente al finalizar la primera semana de tratamiento, nótese la rápida regresión de las lesiones dérmicas.

madre como el hijo. Es de muy rara ocurrencia, siendo excepcional la recurrencia ${ }^{2-4}$. Como en el caso clínico presentado, esta recurrencia se presenta comúnmente temprano y con mayor severidad. Se han descrito cuadros de inicio tan precoz como desde el primer trimestre ${ }^{3,5}$. El curso de la enfermedad es invariablemente progresivo, regresando sólo después del parto con mínimas secuelas tardías ${ }^{4}$.

Clínicamente, la enfermedad se caracteriza por la aparición de placas eritematosas en cuya periferia se desarrollan pústulas dolorosas, estériles, no pruriginosas. Ocurre en gestantes sin antecedentes personales ni familiares de psoriasis, iniciándose comúnmente en el tercer trimestre. Frecuentemente las lesiones comienzan en pliegues inguinales, para luego diseminarse en forma centrífuga abarcando tronco y extremidades. Las mucosas pueden presentar erosiones dolorosas que recuerdan aquellas observadas en el pemphigus vulgaris. El compromiso sistémico puede ser severo incluyendo: fiebre alta, astenia, adinamia, diarrea, deshidratación, delirio, tetania y convulsiones. Estos hallazgos aparecieron parcialmente en nuestra paciente, destacaba en ella la aparición de diabetes gestacional, al parecer secundaria a las altas dosis de glucocorticoides utilizados y que sumado a la intensificación del cuadro base, nos obligó a ensayar un nuevo esquema terapéutico. 
Las pruebas de laboratorio demuestran comúnmente leucocitosis, velocidad de eritrosedimentación elevada y cultivos bacterianos negativos en pústulas y en sangre periférica. Los niveles plasmáticos de calcio, fosfato, albúmina y vitamina $\mathrm{D}$ pueden estar disminuidos.

La apariencia histológica del IH se asemeja a la psoriasis pustulosa, caracterizándose por acúmulos de neutrófilos dentro de focos de epidermis espongiosa, paraqueratosis e hiperplasia psoriasiforme.

El diagnóstico diferencial debe realizarse con psoniasis pustulosa, dermatitis herpetiforme, enitema multiforme, pémfigus vulgaris, dermatosis pustular subcorneal y herpes gestationis ${ }^{4,6,7}$, considerándose como hallazgos claves en el diagnóstico de $\mathrm{IH}$ la presencia de pústulas dolorosas intraepidérmicas estériles, prurito moderado, compromiso sistémico y ausencia de antecedentes familiares ${ }^{7}$.

El tratamiento se basa en medidas de apoyo tópicas y multisistémicas, terapia corticoidal en altas dosis y la interrupción del embarazo con madurez pulmonar comprobada. Como en el caso presentado, cuando este esquema fracasa en el

\section{REFERENCIAS}

1. HeBRA F. Herpes Impetiginiformis. Lancet 1872; 1: 399-400.

2. Henson T, Tul M, Bushore D, Nickolai T. Recurrent pustular rash in a pregnant woman. Archives Dermatology 2000; 136: 1055-60.

3. Beveridge GW, Harkness RA, Luvingstone JRB. Impetigo herpetiformis in two successive prenancies. Br J Dermatology 1966; 78: 106-12.

4. Wolf Y, Groutz A, Wilman I, Luxman D, David MP. Impetigo herpetiformis during pregnancy: case report and review of the literature. Acta Obstet Gynecol Scand 1995; 74: 229-32.

5. Oumeish OY, Farraj SE, Bataineh AS. Some aspects of impetigo herpetiformis. Archives Dermatolology 1982; 118: 103-5. control de la enfermedad y/o aparecen efectos colaterales que otorgan mayor riesgo al binomio madre-hijo (diabetes), se ha aconsejado el uso de ciclosporina por vía oral con buenos resultados materno-fetales ${ }^{8}$.

La ciclosporina es una droga categorizada en «` por la Food and Drug Administration de los Estados Unidos de Norteamérica (FDA) y en estudios en animales es embriotóxica en altas dosis $^{9}$. Sin embargo, en un estudio en 629 embarazadas trasplantadas demostró ser relativamente segura $^{10}$, a pesar de que su asociación con aborto del primer trimestre o restricción del crecimiento intrauterino no pueden ser descartadas. Por otra parte, el riesgo de inmunosupresión en la madre y el feto debe ser cuidadosamente evaluado.

Por la buena respuesta materna alcanzada y por el buen resultado perinatal obtenido en el caso presentado, pensamos que en el tratamiento del $\mathrm{IH}$, frente al fracaso o aparición de efectos colaterales indeseados del esquema terapéutico convencional y luego de una cuidadosa evaluación del riesgo versus beneficio, el uso de ciclosporina es una buena alternativa.

6. WAdE TR, WADE SL, Jones HE. Skin changes and diseases associated with pregnancy. Obstet Gynecol 1978; 52: 233-42.

7. WinTon GB, Lewis CW. Dermatoses of pregnancy. J Am Acad Dermatol 1982; 6: 977-98.

8. Imai $\mathrm{N}$, Watanabe $\mathrm{R}$, Fujiwara $\mathrm{H}$, Ito M, Nakamura A. Successful treatment of impetigo herpetiformis with oral cyclosporine during pregnancy. Arch Dermatology 2002; 138: 128-9.

9. Food AND Drug Administration. 50573s18.PDF. page 10. Disponible en http://www.fda.gov/ eder/ogd/rld/50573s18.pdf.

10. Lamarque V, Leleu MF. Analysis of 629 pregnancy outcomes in transplants recipients treated with Sandimmun. Transplant Proc 1997; 29-2480. 